\title{
REVERSALS OF MISFORTUNE: A NEW SPECIES? OF IDIOGNATHODUS (CONODONTA) BASED ON FUNTIONAL SURFACE MORPHOLOGY
}

\author{
Stamm, Robert G., U.S. Geological Survey, 926A National Center, Reston, VA 22092 USA
}

Idiognathodus (Order Ozarkodinida) is a Pennsylvanian and Early Permian conodont genus of complex ecophenotypic, homeomorphic, and ontogenetic variability. Historically, phenetic taxonomy has created a my riad of "form species" based on long ranging, highly plastic carminate morphologic criteria which provides little or no basis for phylogeny and consequent biostratigraphic utility.

A new species of Idiognathodus has been recognized from the Middle Pennsylvanian (Atokan) of North America and lower Westphalian C strata of Europe. Identification avoids the Idiognathodus carminate platform features and focuses on a frequently overlooked morphologic feature - the blade. Many descriptions and diagnoses of carminate pectiniform blades of the Ozarkodinida provide only minimal information such as lateral profile, degree of attachment, and platform intersection.

Recent studies of microwear faceting, by M. A. Purnell, on the left blade surface of asymmetrically paired Pa elements of Gnathodus bilineatus supports conclusions of ordinal level genetic control of bilateral occlusion of opposed asymmetric pairs, which is consistent with observations of left-behindright element pairing in natural assemblages of known ozarkodinids. Preliminary examinations of discrete element collections and the literature on Pennsylvanian Idiognathodus demonstrate left functional blade surfaces with moderate to strong faceting - with one exception. A new species, first recognized as Idiognathodus sp. A Grubbs (1984) from the upper Wapanuka and Atoka Formations of Oklahoma, exhibits faceting on the right blade surface of asymmetric $\mathrm{Pa}$ element pairs. The right functional blade surface indicates right-behind-left element pairing for bilateral occlusion of asymmetric pairs.

Idiognathodus sp. A Grubbs has been synonymized within broader species concepts indicating that this taxon does not possess the genetic viability in primary ontogenetic morphology to be a distinct entity. Conversely, reversed occlusion as evidenced by functional wear on primary morphology, demonstrates that a genetic transformation occurred. Although identification of this taxon is divest of the usual Idiognathodus $\mathrm{Pa}$ descriptive morphology it will remain synonymized at the generic level until functional morphology is understood in the context of conodont hierarchical taxonomy.

This new species has been identified from middle(?) to upper Atokan strata of Oklahoma, Kentucky, Ohio, Wyoming, and early Westphalian C strata in the Netherlands and United Kingdom. The combination of ease of identification, widespread distribution, and limited stratigraphic range potentially makes this new species a zonal indicator.

Natural assemblages of ozarkodinids provide an important framework for apparatus reconstruction and consequent functional morphology studies, however they grossly under represent the total specific diversity of this group. Discrete element taxonomy provides an immense data set to be coupled with functional morphology and natural assemblages to test the paradigm of apparatus architecture. 